\section{Some Illusions Are More Inconsistent Than Others}

\author{
Jeroen B. J. Smeets $(\mathbb{D}$ and Eli Brenner (D)
}

Department of Human Movement Sciences, Vrije Universiteit

Amsterdam, Amsterdam, the Netherlands
Perception 2019, Vol. 48(7) 638-641 (C) The Author(s) 2019

(c) (1) \&

Article reuse guidelines: sagepub.com/journals-permissions DOI: 10.1 177/0301006619853147 journals.sagepub.com/home/pec

\begin{abstract}
Illusions are characterized by inconsistencies. For instance, in the motion aftereffect, we see motion without an equivalent change in position. We used a simple pencil-and-paper experiment to determine whether illusions that influence an object's apparent size give rise to equivalent changes in apparent positions along the object's outline. We found different results for two equally strong size illusions. The Ebbinghaus illusion affected perceived positions in a way that was consistent with its influence on perceived size, but a modified diagonal illusion did not affect perceived positions. This difference between the illusions might explain why there are so many conflicting reports about the effects of size illusions on the maximum grip aperture during reachto-grasp movements.
\end{abstract}

\title{
Keywords
}

visual illusions, size, grasping, inconsistency, Sander illusion, Titchener illusion, perception/action, two visual systems

Date Received: I February 2019; accepted: 2 May 2019

The Müller-Lyer illusion influences judgments of size, leaving judgments of position unaffected (Gillam \& Chambers, 1985; Smeets, Brenner, de Grave, \& Cuijpers, 2002). We wondered whether this also holds for two other size illusions that are used in the debate on how size illusions influence the reach-to-grasp movement. To find out, we performed a penciland-paper experiment. We asked participants to make marks at lateral positions on a horizontal line that correspond with the sides of an object and reproduce its size by making marks at the corresponding distances from the end of a line. They did so for two objects in

\section{Corresponding author:}

Jeroen B. J. Smeets, Vrije Universiteit Amsterdam, van der Boechorststraat 9, Amsterdam, I08I HV, The Netherlands. Email: j.b.j.smeets@vu.nl 
contrasting configurations of the illusion. We examined whether the effect of the configuration on the reproduced size was also visible in a difference between the separations between the indicated lateral positions.

In total, 82 participants were each provided with two sheets of A4 paper with the same two stimuli and reference lines but with different instructions printed on them. For 42 of the participants, the objects of interest were two $2 \mathrm{~cm}$ diameter orange disks in a standard Ebbinghaus configuration (Figure 1(a)). For the other 40 participants, the objects of interest were two $2.5 \mathrm{~cm}$ black horizontal bars in a modified diagonal illusion (Figure 1(c)), a combination of the diagonal and empty space illusions (Stottinger et al., 2012). Participants used one sheet of paper to indicate the lateral positions of the left side of the left object and the
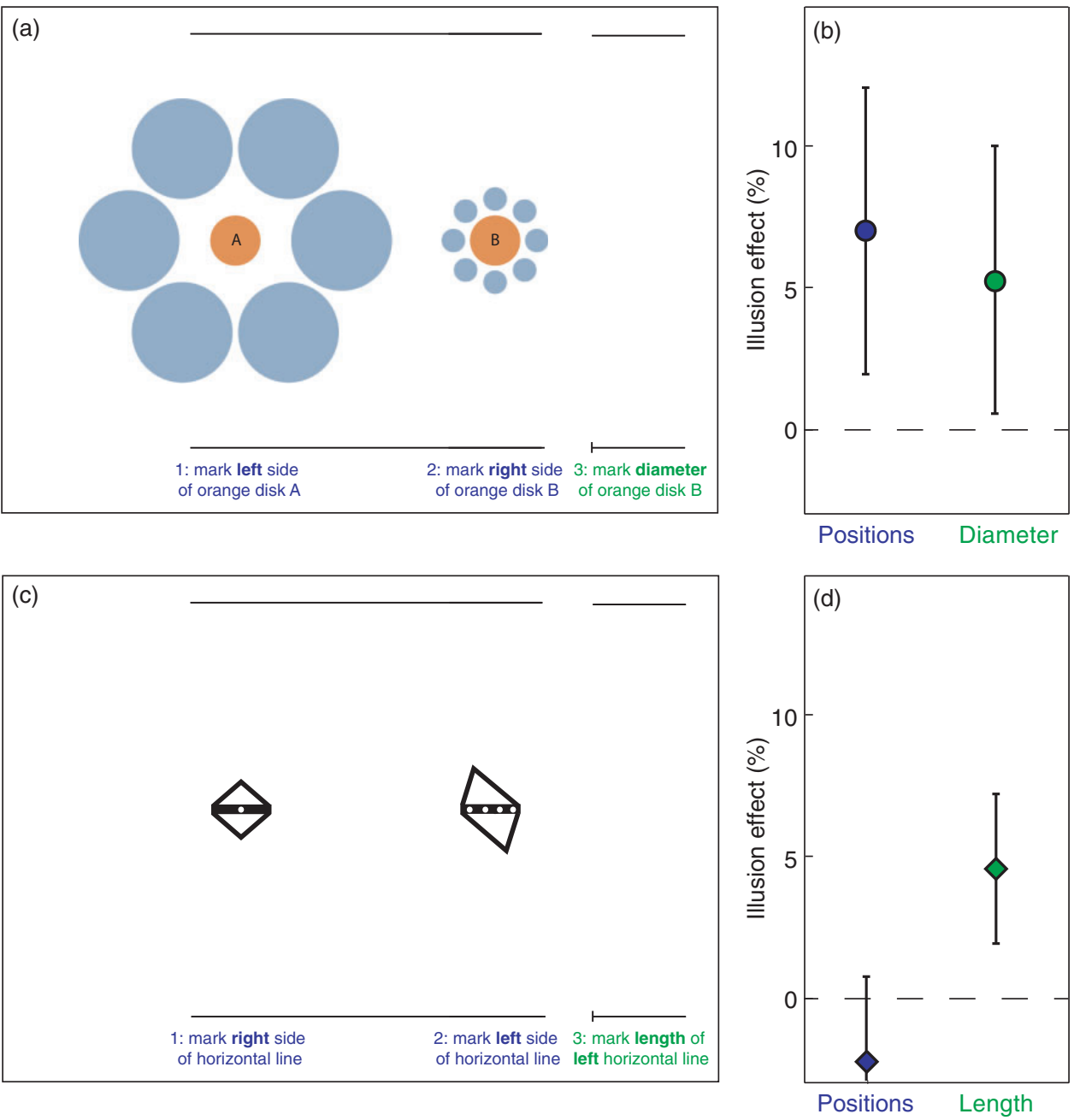

Figure I. Determining two illusions' effects on perceived positions and sizes. (a) Ebbinghaus illusion with the first set of instructions. (b) The Ebbinghaus illusion affected judgments based on positions to a similar extent as those of size (diameter). (c) The modified diagonal illusion (right line seems longer due to the surrounding shape and additional white dots) with the second set of instructions. (d) The modified diagonal illusion only affected judgments of size (length). Text in (a) and (c) is not to scale. Error bars in (b) and (d) indicate $95 \%$ confidence intervals.

Note: Please refer to the online version of the article to view the figures in colour. 
right side of the right object and to indicate the size of the right object. They used the other sheet of paper to indicate the lateral positions of the objects' other sides and the size of the other object. The marks that they made on the paper were used to obtain two judgments of size for each of the two stimuli: a direct size judgment (reproducing the diameter or length) and the distance between the two indicated lateral positions. The illusion effect is the difference between size judgments for the two objects, expressed as a percentage of the actual object size. We removed the data of three participants whose values were more than three standard deviations from the mean.

The effect of the Ebbinghaus illusion was $7.0 \pm 2.5 \%$ (mean \pm standard error of the mean) for the separation between indicated positions and $5.3 \pm 2.3 \%$ for indicated size (Figure 1(b)). This corresponds with an effect size of about $1 \mathrm{~mm}$, which is similar to the values found in other studies (Franz \& Gegenfurtner, 2008). The modified diagonal illusion had a comparable influence on indicated size $(4.5 \pm 1.3 \%)$ but did not influence the separation between the indicated positions (the average effect was even in the opposite direction; $-2.4 \pm 1.5 \%$; Figure 1(d)); the difference between these two measures of the illusion was 6.8 $\pm 1.7 \%$. So, the Ebbinghaus illusion influences judgments of positions in a manner that is consistent with the judged size, but the modified diagonal illusion does not.

We have no idea why the illusions have such different effects on judged positions. However, this difference between the two illusions is consistent with how these illusions influence grasping, provided that grip aperture is based on judged positions rather than on judged size (Smeets \& Brenner, 1999). Peak grip aperture is clearly affected by the Ebbinghaus illusion (Aglioti, DeSouza, \& Goodale, 1995; Franz, Fahle, Bülthoff, \& Gegenfurtner, 2001; Kopiske, Bruno, Hesse, Schenk, \& Franz, 2016; Pavani, Boscagli, Benvenuti, Rabuffetti, \& Farnè, 1999) but not by the empty space illusion or the diagonal illusion (Stottinger, Aigner, Hanstein, \& Perner, 2009; Stottinger et al., 2012).

We were surprised that both the illusions changed the apparent size by about $5 \%$, because the difference in size is much more compelling in the Ebbinghaus illusion than in the modified diagonal illusion. Considering that the Weber fraction for size judgments is about 6\% (McKee \& Welch, 1992; Smeets \& Brenner, 2008), a 5\% size-difference should be barely noticeable. Possibly, the comparison of the two target disks in the Ebbinghaus illusion is not based on perceiving both their sizes independently but on a direct retinal judgment of their size difference. This inconsistency between direct and indirect size comparisons would explain why comparing two objects yields an illusion effect of more than $10 \%$ (Aglioti et al., 1995), whereas summing the effects on individual objects only yields 5\% (Figure 1(b); Franz et al., 2001; Pavani et al., 1999).

\section{Authors' Note}

All data (including scans of all sheets) are available at https://osf.io/3mxsp/.

\section{Declaration of Conflicting Interests}

The author(s) declared no potential conflicts of interest with respect to the research, authorship, and/or publication of this article.

\section{Funding}

The author(s) received no financial support for the research, authorship, and/or publication of this article. 


\section{ORCID iD}

Jeroen B. J. Smeets (D) https://orcid.org/0000-0002-3794-0579

Eli Brenner (D) https://orcid.org/0000-0002-3611-2843

\section{References}

Aglioti, S., DeSouza, J. F. X., \& Goodale, M. A. (1995). Size-contrast illusions deceive the eye but not the hand. Current Biology, 5, 679-685. doi:10.1016/S0960-9822(95)00133-3

Franz, V. H., Fahle, M., Bülthoff, H. H., \& Gegenfurtner, K. R. (2001). Effects of visual illusions on grasping. Journal of Experimental Psychology: Human Perception and Performance, 27, 1124-1144. doi:10.1037/0096-1523.27.5.1124

Franz, V. H., \& Gegenfurtner, K. R. (2008). Grasping visual illusions: Consistent data and no dissociation. Cognitive Neuropsychology, 25, 920-950. doi:10.1080/02643290701862449

Gillam, B., \& Chambers, D. (1985). Size and position are incongruous: Measurements on the MüllerLyer figure. Perception \& Psychophysics, 37, 549-556. doi:10.3758/BF03204921

Kopiske, K. K., Bruno, N., Hesse, C., Schenk, T., \& Franz, V. H. (2016). The functional subdivision of the visual brain: Is there a real illusion effect on action? A multi-lab replication study. Cortex, 79, 130-152. doi:10.1016/j.cortex.2016.03.020

McKee, S. P., \& Welch, L. (1992). The precision of size constancy. Vision Research, 32, 1447-1460. doi:10.1016/0042-6989(92)90201-S

Pavani, F., Boscagli, I., Benvenuti, F., Rabuffetti, M., \& Farnè, A. (1999). Are perception and action affected differently by the Titchener circles illusion? Experimental Brain Research, 127, 95-101. doi: $10.1007 / \mathrm{s} 002210050777$

Smeets, J. B. J., \& Brenner, E. (1999). A new view on grasping. Motor Control, 3, 237-271. doi:10.1123/mcj.3.3.237

Smeets, J. B. J., \& Brenner, E. (2008). Grasping Weber's law. Current Biology, 18, R1089-R1090. doi:10.1016/j.cub.2008.10.008

Smeets, J. B. J., Brenner, E., de Grave, D. D. J., \& Cuijpers, R. H. (2002). Illusions in action: Consequences of inconsistent processing of spatial attributes. Experimental Brain Research, 147, 135-144. doi:10.1007/s00221-002-1185-7

Stottinger, E., Aigner, S., Hanstein, K., \& Perner, J. (2009). Grasping the diagonal: Controlling attention to illusory stimuli for action and perception. Consciousness and Cognition, 18, 223-228. doi:10.1016/j.concog.2008.04.003

Stottinger, E., Pfusterschmied, J., Wagner, H., Danckert, J., Anderson, B., \& Perner, J. (2012). Getting a grip on illusions: Replicating Stottinger et al Exp Brain Res (2010) 202:79-88 results with 3-D objects. Experimental Brain Research, 216, 155-157. doi:10.1007/s00221-011-2912-8 